Meta

Journal des traducteurs

Translators' Journal

\title{
Quality Assurance for Interpreting Processes
}

\section{Sylvia Kalina}

Volume 50, numéro 2, avril 2005

Processus et cheminements en traduction et interprétation

Processes and Pathways in Translation and Interpretation

URI : https://id.erudit.org/iderudit/011017ar

DOI : https://doi.org/10.7202/011017ar

Aller au sommaire du numéro

\section{Éditeur(s)}

Les Presses de l'Université de Montréal

\section{ISSN}

0026-0452 (imprimé)

1492-1421 (numérique)

Découvrir la revue

\section{Citer cet article}

Kalina, S. (2005). Quality Assurance for Interpreting Processes. Meta, 50(2), 768-784. https://doi.org/10.7202/011017ar

\section{Résumé de l'article}

Cet article porte sur la qualité en interprétation de conférence. Après la discussion des rôles assumés par les différents interactants et leurs préférences ainsi que des conditions d'interaction dans lesquelles le travail de l'interprète se situe, une grille de paramètres est proposée qui peut servir à assurer la qualité pour chaque interprète ainsi que pour ses clients. L'objectif est de contribuer à la gestion de la qualité en coopération des interprètes avec les autres participants d'une conférence, coopération qui peut améliorer l'interprétation ainsi que la communication multilingue. 


\title{
Quality Assurance for Interpreting Processes
}

\author{
SYLVIA KALINA \\ Cologne University of Applied Sciences, Cologne, Germany \\ sylkalina@aol.com
}

\begin{abstract}
RÉSUMÉ
Cet article porte sur la qualité en interprétation de conférence. Après la discussion des rôles assumés par les différents interactants et leurs préférences ainsi que des conditions d'interaction dans lesquelles le travail de l'interprète se situe, une grille de paramètres est proposée qui peut servir à assurer la qualité pour chaque interprète ainsi que pour ses clients. L'objectif est de contribuer à la gestion de la qualité en coopération des interprètes avec les autres participants d'une conférence, coopération qui peut améliorer l'interprétation ainsi que la communication multilingue.
\end{abstract}

\begin{abstract}
This article discusses how the quality issue in conference interpreting can be approached using a scheme for quality assurance. Participants in conferences have different roles and not always the same preferences, while interpreters depend on speakers and may have to work for heterogeneous audiences. On the basis of a model of mediated multilingual conference communication, interpreting processes and conditions can be analysed with the aid of a list of parameters; the list can be used by clients and conference interpreters for their overall and personal quality assurance.
\end{abstract}

\section{MOTS-CLÉS/KEYWORDS}

quality assurance, source text, target text, communicative situation, methods of assessment

\section{From 'good interpreting' to quality assurance}

The quality of interpreting services is an issue which confronts interpreters, interpreting trainers, users and researchers with considerable problems. Interpreters and trainers feel that they can assess the quality of colleagues or trainees intuitively, on the basis of their experience and professionalism, but they are unable to express their subjective judgements by objectively measurable standards. Users may not trust interpreters as they are unable to control their rendering. Researchers have not been able to agree on a universal, generally accepted quality model applicable to conference interpreting, or any type of interpreting at all for that matter.

These factors appear to make quality assurance (QA) for interpreting well-nigh impossible, as QA necessitates a method of assessing quality that is transparent and objective. In the context of written translation, translators have meanwhile developed certain agreed standards according to which they can work and assess translations; these standards refer to the translation product as well as to the processes by which translations are produced (ISO 9002, DIN 2345, European Code of Best Practice). Interpreting, however, takes place under extreme time constraint, and interpreters have to solve as many problems as possible before they actually interpret by anticipating potential solutions to such problems. For this reason, QA must also cover 
what happens before and after the interpreting act as such, as these phases may have a significant impact on interpreter output.

In an age of quality management which avails itself of all kinds of continuous evaluation and quality control, interpreting is but one of many services the quality of which is essential and must be guaranteed. Conference interpreters expect to be paid adequately and those who pay for their services have a justified interest in seeing that they get good quality. Interpreters cannot afford to refuse to subject their work to QA on grounds of its ephemeral nature; on the contrary, it is in their own interest that QA should be an efficient instrument of guaranteeing that their services are assessed for what they are and that good as well as poor interpreting quality can be identified as such (Moser-Mercer 1996, Kalina 2002, Mack 2002).

Most interpreting researchers' publications devoted to the quality of interpreters' services have focussed on interpreters' output; some adopt new approaches, also discussing types of interpreting that had long been neglected (cf. Pöchhacker 1994 and 2001, Vuorikoski 2004 and others). This article is about conference interpreting, but QA is a requirement for other types of interpreting too, and the author's aim is to develop a concept which can be applied, with necessary adaptations, to all types of interpreting.

For the purpose of this article, I shall approach QA from the following points of view: (1) that of the potential employer and client and of the evaluator at formal examination sessions, (2) that of the researcher, (3) that of the user of the service in question, and (4) that of the individual interpreter. In the early period of simultaneous interpreting (SI), after World War II, the recruiters of candidates for interpreting at the Nuremberg Trials tested interested bilinguals for skills such as mental concentration, fluency, composure, alertness and clear enunciation (Koch 1992: 2). As the profession developed, it was felt necessary to address the quality of the service to be rendered by interpreters within the scope of professional associations, first and foremost AIIC (Association Internationale des Interprètes de Conférence). This worldwide professional association established its own admission committee and defined membership criteria which were intended to serve as guidelines for the schools that train conference interpreters (cf. www.aiic.net).

With the growing need for interpreters to work for international organizations, above all the (then) European Communities, recruitment was based on entrance tests administered to university graduates to ascertain their simultaneous and consecutive skills and general knowledge of the EU so as to make sure that quality interpreting would be provided. In many countries, national public authorities recruiting conference interpreters also started testing their future interpreters by making them interpret short impromptu speeches, sight translating, etc. In all these procedures, the basis for the assessment of quality or proficiency is a source text, against which the interpreter's orally produced target text is measured with a view to its acceptability to potential users. No recordings or transcripts are made of either source or target text, and assessment is made on the spot, taking into account parameters of spoken language production such as smooth delivery, communicative speaking and voice quality. Again, there is no set of uniform criteria for this type of assessment, and sometimes candidates are left with numerous questions as to the reasons why they failed a particular test.

In assessment procedures at examination sessions at university training institutions, examiners are faced with similar problems; they are aware of the artificial 
character of the situation and its potential effect on candidates' interpreting quality and also of the often necessarily subjective character of their assessment. Therefore, a quality requirement for such examinations is that examiners assess candidates in panels so that the subjective character of individual ratings is made up for by the number of opinions given. Nevertheless, assessors are often at a loss when they have to put their individual judgements into the wording of legally incontestable, formal reporting language.

After the simultaneous mode of conference interpreting had begun to replace the time-consuming consecutive mode that had hitherto dominated bi- or multilingual international conferences, SI became the object of research by scientists from various disciplines, and the question of the quality of the output produced in the simultaneous mode turned out to be the most attractive issue. The approach chosen by the early researchers was a comparative linguistic one, with experimental interpreting recordings being made and the results being transcribed and compared with their originals. The research parameters of these studies were defined in terms of criteria such as number of correct or deleted words and syntactic equivalences (para- vs. hypotactical structures); at the semantic level, propositions and their content were chosen as parameters for interpreting quality. However, source texts were not always speeches, settings were not always conferences, interpreters were not always professionals, and research parameters were not always conclusive for interpreting research (for an overview of the literature see Kalina 1998). At this early stage of interpreting research, the situation (e.g. what was interpreting needed for?) and classification of those involved in the process, namely speaker (intention and presentation), interpreter, listener (how does their processing work?) and text type were not yet taken into account.

It was only several years later that interpreters started to devote themselves to scientific research and considered factors of real-life interpreting in their approaches. Today, there are a number of different approaches to interpreting and its quality, each emphasizing specific aspects of the process or product. Gile (1988) defines interpreting quality from a processing view as the optimum balance between different processing efforts, and explains deterioration in quality as caused by an excessive constraint on total processing capacity due to overloading of one of the processing efforts (listening, memorization, or speaking). This deterioration becomes apparent as a loss either of information or of linguistic form or clarity or coherence in the interpreter's output. If interpreting quality is defined as appropriate strategic processing (as in Kalina 1998), the deterioration of quality indicates that strategic processing becomes more difficult or has broken down, i.e. paraphrasing, generalization, etc. do not lead to an adequate target text. However, the problem lies in determining exactly which type of loss of quality is due to which kind of overload or strategic error, and in establishing whether there is any measurable relationship between them.

From the point of view of a professional-turned-researcher, Pöchhacker (1994) defines quality within the framework of a hypertext situation, "hypertext" referring to the conference setting as a whole. The quality of interpreter output is described as one aspect of communicative interaction and discourse quality. The quality definition proposed by Mack (2002) is that of an evaluator. Interpreting, as translation, is the transfer of textual information between two languages; it requires the skill of being able to establish equivalences in terms of content, shape and performance. As a special 
type of interlingual communicative act in a complex social network of relations, it is an effort, on the pragmatic level, at achieving speech acts with optimum effect. Quality could then be measured as the rate of success in this effort.

\section{In search of ideal interpreting quality}

In her attempt to address the quality issue empirically, Bühler (1986) points out that an ideal quality of output can only be defined for a specific situation (cf. also Mack 2002: 112). The question that needs to be answered, however, is how exactly this can be done. Shlesinger (1997) emphasizes the need for QA but also its dependence on shared norms of interpretation; the only point on which all agree is that quality may mean very different things to different persons.

For Moser-Mercer, a prerequisite for any notion of interpreting quality is a definition of what conference interpreting is. What an interpreter does is to make communication possible, convey speakers' concepts in another language, prepare subject and terminology, and abide by the ethical code of the profession. Optimum quality is "the quality an interpreter can provide if external conditions are appropriate" (MoserMercer 1996: 44) This means that "[...] an interpreter provides a complete and accurate rendition of the original that does not distort the original message and tries to capture any and all extralinguistic information that the speaker might have provided subject to the constraints imposed by certain external conditions" (Moser-Mercer 1996: 44). As to quality evaluation, she describes the different points of view from which quality can be assessed, i.e. those of the interpreter him or herself, serviceproviders, users, intermediaries, and trainers. Assessment by all these groups might yield a very heterogeneous picture depending on what exactly they want to know (Moser-Mercer 1996: 46). Likewise, Kopczynski (1994) defines quality as a function of situation and context, variables which might call for different priorities in different interpreting situations. In an effort at widening the perspective to include other types of interpreting, Pöchhacker sees the common denominator of all types of interpreting in the fact that the interpreter "[...] supplies a textual product which provides access to the original speaker's message in such a way as to make it meaningful and effective within the socio-cultural space of the addressee." (Pöchhacker 2001: 421) This dimension is also addressed by Mack with reference to community interpreting (Mack 2002: 114), where interpreters are generally expected to act on behalf of the weaker party.

Pöchhacker (2002) defines the criteria for the product and the service rendered; the most significant quality standard is the success of the communicative interaction, with equivalence of intended effect, adequacy of expression and accurateness as compared with source text ranking next in that order. For Vuorikoski (2004), "sense consistency with the original" is the one defining property of good conference interpreting. Another theoretical approach to quality is presented by Garzone, who addresses the variability of norms and quality criteria that underlie any determination of quality across cultures, space and time (Garzone 2002: 115). For her, quality assurance is the sole responsibility of the interpreter, as he/she is accountable for the "finished product" (Garzone 2002: 118). This is in contrast to Vuorikoski who argues that for interpreting quality to be achieved, it is necessary for the speaker and the interpreter to cooperate (Vuorikoski 2004: 88). 
As for the market view, international organizations, above all SCIC (the joint interpreting services of the EU Commission and Council) often deplore a quality gap between the skills they expect from conference interpreters to master and those offered by university graduates. A closer look at the complaints (cf. Interim Report of the IAMLADP working group on training of language staff, UN Office at Vienna, 2001) reveals that the recruiters in question mostly refer to language combinations that are not suitable for their needs, a factor that is not at the core of the quality question as discussed here even though it is an important concern for them as employers.

Professional interpreters sometimes complain about beginners' quality by citing their lack of routine and market experience, a circumstance which they can help overcome by including young university graduates in their teams initially as 'silent' (i.e. observing) members. Another aspect of professional conference interpreting is that practitioners rarely compare the output of their colleagues - or for that matter, their own output - with the standards they defend. On the other hand, principles of professional ethics, which have been developed by the professional organizations, require every interpreter to ascertain the quality of his or her output by appropriate measures, e.g. self-evaluation by means of self-recordings (Déjean Le Féal 1990: 156f).

The authors referred to agree that quality of interpreting is not an absolute standard that can be reached at any time in any circumstances. Rather, it is a balancing act between the aspirations, expectations and requirements of different and even heterogeneous groups. Interpreters often have to choose between one of two (or several) objectives: faithfulness to the original or comprehensibility for the listeners, correct language or accurateness, elegant style or completeness. And the question of how to measure successful communication or interpreters' effort in conveying the message remains unsolved.

\section{Output as a function of the original}

From the time of purely consecutive interpreting to the large numbers of simultaneously interpreted multilingual meetings held on a daily basis in our times, the nature of conference subjects has changed and topics have become much more complex and specialized. Moreover, with the use of English as a lingua franca by many non-native speakers whose languages are not among the conference languages offered and whose English is not always such that they can expect their ideas to be understood by those listening to them, the quality of the original on which interpretation is based has also become a crucial factor for the quality of interpreters' output.

Most comments on ST quality refer to "spoken vs. written style" (e.g. Déjean Le Féal 1982, Vuorikoski 2004), delivery characteristics including segmentation and speed (Shlesinger 1994, Pöchhacker 1994) and highly personal features such as monotony of speech, hesitations, non-native accents and others. These factors cannot be influenced by interpreters but are likely to affect interpretation quality. The speaker therefore bears a certain responsibility for interpreting quality, too, as do others that act within the framework of the overall speech situation (cf. also Vuorikoski 2004: 25).

The following examples from conference situations serve to illustrate some of the problems interpreters are permanently faced with; they also show that remedying deficiencies is not always in their control and point to what can be done to optimize the interpreting product and make an event more communicative. 
Where (a) a speaker reads out text fast, so that even the source text audience has difficulties in following, or (b) speaker's language is dense, implicit in character, whereas target language tends to be redundant and explicit, or (c) speaker quotes complex text passage or reads out figures, names, acronyms which have not been made available to interpreters, prior advice to speakers and conference organizers (above all those responsible for conference processes) if it is offered sufficiently in advance and with the appropriate reasoning, sometimes, though not always, helps.

When (d) a speaker commits a speech error (e.g. 'Czechoslovakia' instead of 'the Czech Republic,' or mixing up 'to commend' with 'to condemn'), or (e) uses language which would be judged offensive in target culture, or (f) uses metaphors, puns or figurative speech for which there is no equivalent in target language, it is the skill and intercultural as well as strategic competence of the interpreter which determines the TT solution, and whatever the case, processing effort has to be stepped up (cf. also Van Besien \& Meuleman 2004).

If (g) a speaker loses his or her thread or (h) is linguistically vague or (i) intentionally ambiguous, even for the ST audience (maybe to test audience response), the interpreter is sometimes compelled to produce apparently poor TT quality and may even risk being held responsible for it.

If ( $j$ ) a speaker comes to an end, but the next speaker or chairman does not wait for the interpreter to complete output (this happens systematically in EU and TV settings), it is the responsibility of the organizers or moderators to improve floor discipline.

Vuorikoski, referring to the fact that in the European Parliament, the President or Chair does not even wait, after a speaker has come to an end, for interpretation to follow but immediately calls the next speaker (2004: 126), concludes that "Speakers should take into account the fact that their speeches are being or are to be interpreted" (ibid.: 252). In line with the above, the author of the present article would argue: anyone involved in the communication situation should take this into account and act accordingly.

Despite numerous efforts (e.g. by SCIC and AIIC) at advising speakers that, when presenting their contribution within the framework of an interpreted conference, they should speak clearly, slowly, separate ideas, avoid puns and allusions which cannot be understood by all, most people who speak at conferences have other things on their minds than interpreters' problems. Although this should not cause the profession to give up repeating these points again and again, we must face the reality of originals whose quality may not always be ideal. Trainees are often advised that in the case of a poor speaker, they, as interpreters, should improve on linguistic form while preserving the content of the message. However, some deficiencies that a ST may have (speaking rate, poor articulation, accent, incorrect words or expressions) will make the interpreter's task more difficult in that his or her comprehension effort needs to be increased, taking more attention away from one or several aspects of TT production (cf. Gile 1988). Other effects may range from misunderstandings owing to imprecise pronunciation (e.g. poetry/portrait) with resulting higher monitoring effort and possibly error or deletion of elements that have not been processed. Such effects clearly show the extent to which TT production depends on input, i.e. ST features, which have to be taken into consideration when determining TT quality. After all, speakers are not always aware that their message, which is addressed to a 
well-defined audience, has to be understood by a linguistic mediator, who probably does not have the knowledge the speaker presupposes the audience to have.

On the basis of a typology of source texts, Pöchhacker suggests a set of textdelivery properties (oral/written form, rhythm, voice and articulation, pauses, hesitations) that can be applied to source texts as well as target texts, with certain properties of target texts resulting from certain properties of source texts. With such a methodology, ST delivery profile and its resulting surface quality can be accounted for in assessing interpreting quality (1994: 218ff).

\section{Output as perceived by users}

The output of any interpreting is intended for those listening to the interpreters. It is therefore evident that listeners' needs and expectations are central to the discussion of quality. Vuorikoski sees the emphasis of SI quality assurance on addressees of SI and their needs (2004: 24). However, listeners' expectations may differ from those of speakers (cf. Kopczynski 1994).

Some authors suggest that an important criterion for a good target text is that it can be understood and be seen as an autonomous text in its own right (Pöchhacker 1994: 216). For Vuorikoski, studying interpreting quality means “...to investigate whether the substance of the ST argumentation, including the speech act of the original speech, has been conveyed by the interpreters, thereby allowing listeners of interpreting to create an impression of the speech which is equal to the one they would have created had they been listening to the original speech directly" (Vuorikoski 2004: 71) This means that the effect of a source text on ST listeners should be identical to the effect of the corresponding target text on TT listeners. However, does such a postulate acknowledge that the effect produced on a group of TT listeners may be different for other reasons than interpreting, e.g. on cultural grounds? An example illustrating this point would be a scientific lecture given by a German-culture speaker to a mixed audience of German- and English-culture listeners. The highly scientific jargon and complex discourse structures frequently used by German scientists would have a different effect on those in whose culture such a lecture tends to be presented with less complexity and jargon than on those for whom such an approach constitutes the norm. In this connection, there is a further research problem. i.e. to find a methodology for measuring whether a postulated effect has been achieved.

As has been argued before, processing of incoming texts, including orally presented texts, is done very differently by different people. This is also true if texts are relayed by interpreters. People who listen to their target texts will have different personal and other preferences, a circumstance that has been confirmed in numerous user surveys (for an overview of these, cf. Kurz (2001), who also discusses some of the methodological problems). Listeners' interest is not necessarily focussed on interpreter delivery but on the source message; their preferences may be determined by cultural habits, knowledge of and interest in a given subject, personal attitudes and subjective impressions.

User surveys also reveal that users' responses to questionnaires are not necessarily consistent with their preferences in the conference room (cf. Kahane 2000, Kurz 2001, Mack 2002). Paradoxically, Bühler (1986), whose first survey was conducted among interpreters themselves, found that one of the parameters, 'team skills,' was 
given a low rating, although one would expect that group to be most interested in team skills since they are always working with fellow interpreters in their booths.

Another problem with user surveys is that users will assess interpreter output according to the standards they know from monolingual communication. These standards, however, are insufficient, as they do not provide for the fact that in bi- or multilingual mediated communication, a relaying intermediary (the interpreter) listens to a ST which is not addressed to him/her. The interpreter then produces a TT without the usual semantic autonomy or structural and linguistic control over the product (cf. Kohn \& Kalina 1996). For the TT listener, it is impossible to judge which of the factors that guide his/her assessment are to be attributed to which text producer, i.e. original or interpreter.

During their training, interpreters are often advised to adapt their output to the needs of their listeners; but, as mentioned above, there may be very different subgroups within a given audience that is listening to the same language version. Snelling (1989: 42) suggests a typology of target groups, an approach which helps when they are more or less homogeneous; the problem remains that adapting output to the needs of, say, a group of non-native listeners, making a source text more comprehensible for that group, may imply compromising on style and linguistic variability and thus fail to meet the expectations of native listeners.

\section{An integrated approach to quality assurance}

\subsection{The concept of mediated multilingual communication- and $(f)$ actors involved}

It has become clear that interpreting quality is an issue that centres around source and target texts but includes many aspects that cannot be explained by simply comparing the two. We therefore need other methods of analysis to shed light on those factors that have an impact on quality without necessarily being obvious to the eyes of those involved. Pöchacker (1994) describes dimensions of interdependencies between the different actors and texts. Shlesinger (1997) points to the need to examine interpreter output (TT) on an intertextual level (comparison of ST and TT), on an intratextual level (TT in its own right) and on an instrumental level (usefulness and comprehensibility of TT). The latter aspects are also discussed by Viezzi, who stipulates four criteria for evaluating interpreting quality: equivalence, accuracy, appropriateness and usability for the audience (Viezzi 2003: 146); the first two parameters can be measured by comparing ST and TT, whereas the other two require information from users.

The very concept of quality, as defined in ISO standard 8402, refers to properties and characteristics of a product or a service and to the fulfilment of standards defined beforehand (Mack 2002: 110f). For Mack, any agreed definition of quality depends on the position that interpreting assumes in a given culture. Is the interpreter guided by the speaker's norms and expectations, or is he or she rendering the service in such a way as to do justice to both speakers and listeners? (ibid.: 113) One might even ask a third question, i.e. is the interpreter the mediator for one of the parties involved, if he or she has been hired by that particular party, for example, and has been given certain instructions for his or her actions? 
In most of the literature, the term 'customers' is understood to mean 'listeners,' addressees of the message. However, there are other interests and people involved in getting messages across at conferences. For this reason, Kalina (1995) suggested a framework for approaching the question of assessing interpreter output which takes into account the interests and motivations of different parties to a communication act. Kutz (1997: 243) draws attention to the fact that assessments of interpreting quality always depend on the intention by which an assessment is made, be it by one of the user parties, the researcher or the trainer/examiner. In Kohn \& Kalina (1996), a broader, psycholinguistically oriented concept is developed which sees interpreted communication as a complex process of discourse-based mental modelling that involves production and comprehension by the different participants in communication. Against this background, strategic choices available to interpreters can be described and quality can be related to the choices an interpreter makes in a given situation.

FIGURE 1

Bilingual, interpreter-mediated conference communication

Organizer / Client / Employer

Main interest: success, cost/benefit, effect

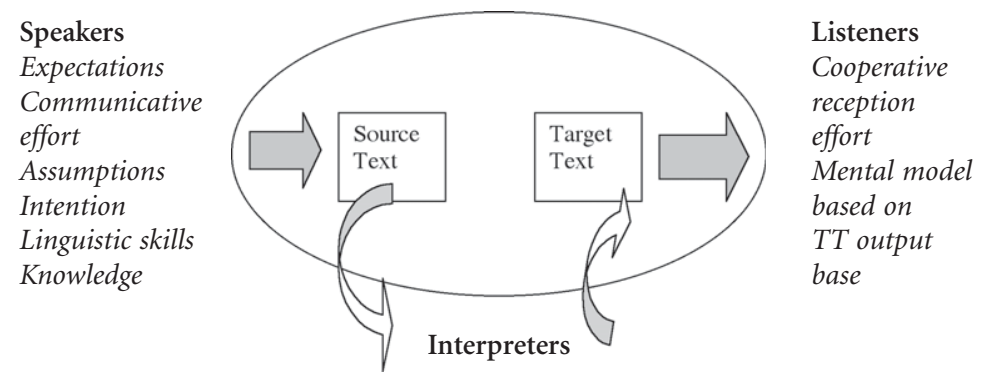

Mental model, knowledge base, linguistic expertise, interpreting skills

If interpreters are expected to transfer the semantic, connotative and aesthetic content of the original message and use the lexical, syntactic and stylistic resources of the target language to do so (Vuorikoski 2004: 54), then any evaluation of the quality of the result has to cover all these dimensions. That is why user surveys are insufficient tools to determine interpreting quality, as they reflect only one relationship in a communication situation. Speaker delivery, technical conditions and client or user preferences have to be considered as well. Interpreters have an interest in being able to include in any evaluation or assessment all factors that may affect their output.

On the other hand, if interpreters are expected to pursue their own quality control, they are faced with a number of problems. ST and TT are not always accessible (if no recordings can be made) and are not intended for any other use than to be listened to at the conference. There is still no methodology or set of criteria which they could apply.

Diachronic comparison is made difficult by the fact that conditions vary considerably from one event to another. It appears to be almost impossible to obtain all the data needed for an objective assessment. In view of these problems, Mack (2002: 116f) proposes an approach which starts with the macro-level of the framework of commu- 
nication (has communication among all participants been successful? Cf. Pöchhacker's hypertext approach), the following level is that of individual contributions (has the degree of informativity and the effect been equivalent?); then going down to the micro level of segments of speech (was the output coherent and comprehensible?). This is the level Pöchhacker aims at measuring, though as a relative parameter, with what he defines as "propositional accuracy scores" (Pöchhacker 2001: 417).

\subsection{A model of interpreting conditions and processes}

Quality assurance for interpreting requires quality management to be carried out by individual interpreters, team organizers and conference organizers alike. In this, attention must be given to the requirements and expectations of all participants involved in a communication act as related to the service rendered by interpreters. These requirements refer to interpreter output and its effect but also to structures, processes and conditions which have an indirect effect on output but are likely to have a bearing on interpreting quality.

On the one hand, such quality management will have to refer to macro-level parameters, as described by Kopczynski (1994), who integrates the different contextual and situational perspectives by focussing on pragmatic factors, the main variables being the speaker (status, intention, attitude towards listeners), listeners (attitude towards speaker, his/her message) and interpreter (skills, judgements, attitudes, strategies and message, its form and illocutionary force) as well as existing interactional norms and communication situation or setting. As Kopczynski puts it, priorities have to be redefined for every single situation as it occurs. With such an approach, larger numbers of texts can be analysed (as in Vuorikoski 2004). On the other hand, quality assurance also has to rely on microtextual analysis, measuring the target text by its equivalence or correspondence to a given source text, identifying strategies, linguistic proficiency and the solution of translation-specific problems.

As we have seen, the quality of interpreters' output depends on a multitude of conditions governing the communication situation in question. Some of these have to be fulfilled by others involved in the communication (external conditions) but some have to be fulfilled by the interpreter. Several conditions are determined by external factors without the interpreter having any influence on them, such as speakers' rhetoric skills and presentation rate (delivery speed) as a function of the grammatical structure of the source text. Such factors cannot easily be detected by the recipients of the interpreters' output but nevertheless affect output quality and have to be accounted for in a quality model. Interpreting quality is also a function of interpreters' knowledge of situational as well as contextual variables and of speakers and their intentions. Moreover, interpreters should know who the listeners are (experts, TV audience, politicians, etc.) and what their interests are, what their mother tongues are, which hierarchies obtain in the communication situation, etc. In this connection, one of the factors to be identified is therefore the degree of preparation which interpreters invest in their assignments. It is true that there are a few prodigies who arrive at a meeting, ask their colleagues about the theme of the conference and start working successfully. In most instances, however, such a way of proceeding would result in poor quality, ignorance of in-house jargon and technical terms and failure to build a mental representation of incoming text on the basis of previous knowledge. 
Preparation prior to the event is as crucial as is the terminological follow-up or selfevaluation after the event.

In light of all that has been said above, a wider framework is needed to be able to define or indeed evaluate the quality of interpreting, and this has to take into account processes preceding and following the interpreting act. Such an approach includes

(1) a pre-process phase that includes trained interpreting skills and competences, information retrieval and preparation as well as coordination or cooperation with other members of a team,

(2) a peri-process framework which includes the conditions in which the interpreting act takes place (data on participants, working languages, team composition, possible relay requirements, documents made available in-conference, time schedules, technical equipment),

(3) in-process requirements to be met by interpreters, speakers, listeners, technical staff, etc. and

(4) post-process activities (for a detailed discussion see Kalina 2002, 2004).

Within this framework, quality can be regarded as a multi-dependent variable; the more conditions are met in the relevant phases, the better interpreting quality should be, provided that interpreters have full command of languages, subjects under discussion and translation strategies.

\subsection{A step towards implementing quality assurance}

In international organizations such as the EU and UN, booths are manned with mixed teams of permanent staff and freelancers. The permanent staff benefit from quality assurance measures taken by the organization but freelancers have to manage their own quality assurance. For instance, freelance interpreters do not normally participate in programmes of in-house training (specialization, language-enhancement courses, etc.) that are offered to the permanent staff.

QA is also faced with a challenge by the current trend of placing interpreting booths farther and farther away from speakers' platforms; various bodies plan to introduce remote interpreting, a situation which makes it increasingly difficult for interpreters to be aware of all interaction in the conference hall, let alone to see the speaker and read from his or her lips. It must be clear to those devising such arrangements that either they have to provide for technical equipment that can make up for physical distance or interpreting quality will suffer.

Another challenge to interpreting quality is the number of languages from which (and into which) an interpreter is expected to work. On the freelance markets of those countries where conference interpreting is in demand, interpreters rarely work from more than two languages; many interpreters with English as one of their working languages have even opted for only this language and their native language to work from and into (A-B-A). Many interpreting schools do not train their students to work from A to B in the simultaneous mode. The linguistic services of the EU and other international organizations, on the other hand, require their interpreters to work from a minimum of three, if not more languages. The quality problem arising in this connection is obvious; the higher the number of languages an interpreter is expected to master, the more limited the thorough knowledge of all linguistic nuances of each of them and the awareness of cultural differences, of the 
literature and traditions, etc. This becomes particularly evident when EU interpreters who, for decades, had to interpret only into their A language (a principle without which working from that many source languages would not be possible), are now increasingly expected to perform retour interpreting (i.e. to work also into their B language), a policy which is bound to affect quality. With QA as proposed above, such trends can be documented, action can be taken if quality deterioration is detected and its causes can be identified.

In the following, an attempt is made to adapt the approach described in section 5.2 to quality assurance needs of professional interpreters. The first objective of the data sheet presented below is to make practising conference interpreters aware of the role played by the factors in question when they strive to attain optimum quality. A desired consequence of such awareness would be for interpreters to keep track of their assignments by documenting the conditions of each event at which they worked, so as to be able to trace weak points that arose either in external conditions or in their own effort and to optimize them. Besides serving as a QA tool, documentation of this kind may also help researchers obtain more data on real-life scenarios of interpreting and review their models accordingly.

As presented here, the data sheet is a very rough tool; it can be refined and adapted depending on which component of the overall process is to be analysed in detail.

FIGURE 2

QA data sheet on interpreting assignments

\begin{tabular}{|l|l|l|}
\hline Parameters & Type of data to be measured & Result \\
\hline Pre-process & Contract & \\
\hline Inquiry received & Date vs. date of event & \\
\hline Inquiry channel & Telefone, e-mail, others & \\
\hline Source/origin of inquiry & Recommendation, professional association & \\
\hline Specificity of inquiry & $\begin{array}{l}\text { Number of languages, directions, sessions, } \\
\text { interpreting mode, subject matter etc. }\end{array}$ & \\
\hline Languages requested & Number & \\
\hline Language directions requested & Number & \\
\hline Advisory effort invested & Hours, materials, questions asked & \\
\hline Time and effort spent on negotiating & Point of departure vs. end result & \\
\hline Technical assistance & Time invested, recommendations made & \\
\hline Drawing up of quotation & Degree of detail, contact with colleagues & \\
\hline Contract signed & Contract date vs. date of event & \\
\hline Contractually agreed languages & Number & \\
\hline Language combinations & Number & \\
\hline Language directions & Number, specification & \\
\hline Contracts sent to team members & Number of team members, date & \\
\hline Receipt of signed contracts & Date, correctness & \\
\hline Booths & Number, standards & \\
\hline Interpreters & Number & \\
\hline Professional ethics & Principles, membership of prof. assoc. & \\
\hline
\end{tabular}




\begin{tabular}{|l|l|l|}
\hline & Preparation & \\
\hline Subject matter information & Available when and how? & \\
\hline Information specificity & URLs, reference mat., manuscripts, charts & \\
\hline Material received & List of dates of received documents & \\
\hline Consultation with client & Time invested, content & \\
\hline Contact with team members & Accessibility, time taken to respond & \\
\hline Document distribution & $\begin{array}{l}\text { Selective distribution vs. 'everything to } \\
\text { everyone' }\end{array}$ & \\
\hline Team and working schedule & Schedule of work for each interpreter & \\
\hline Heads of booth and team & Names & \\
\hline Coordination between booths & Head of team & \\
\hline Special arrangements & Details & \\
\hline Time invested in preparation & Hours per interpreter & \\
\hline Preparation sources & Client, internet, others & \\
\hline Media used for preparation & Dictionaries, glossaries, data bases, etc. & \\
\hline Speaker-specific preparation & Type, detail, with manuscript or charts & \\
\hline Briefing & Length, intensity, source & \\
\hline Preparation coordination & Division of work, fair-share principle & \\
\hline
\end{tabular}

\begin{tabular}{|l|l|l|}
\hline Peri-process & Data on assignment & \\
\hline Travel arrangements & Contractual details, hours & \\
\hline Punctuality & If applicable, date of arrival & \\
\hline In-conference coordination & Problems, solutions & \\
\hline Equipment test run & Yes/no, problems to be specified & \\
\hline Functioning of technical installations & $\begin{array}{l}\text { Acoustics, video/audio transmission, } \\
\text { microphones, technical service }\end{array}$ & \\
\hline Number of booths, interpreters & Number, names & \\
\hline Transmission channels & Direct, recording, TV, etc. & \\
\hline Cession of copyright & Extent, purpose & \\
\hline Available languages & Language combinations & \\
\hline Language directions used & Lengths of languages spoken/ listened to & \\
\hline Interpreting turns & Number, length of turns per interpreter & \\
\hline Number of speakers / listeners & Attendance list, number of headsets used & \\
\hline Degree of interactivity of event & $\begin{array}{l}\text { Number of floor contributions, hours of } \\
\text { discussion }\end{array}$ & \\
\hline Assignment duration & $\begin{array}{l}\text { Total length of event, actual need for } \\
\text { interpretation }\end{array}$ & \\
\hline
\end{tabular}

\begin{tabular}{|l|l|l|}
\hline In-process & Conditions, factors & \\
\hline Profile of event & Type of conference & \\
\hline Structure of interaction & $\begin{array}{l}\text { Hierarchical, flat, expert panel, expert to } \\
\text { laypeople, etc. }\end{array}$ & \\
\hline Booth position & Vision from booth, perceptibility & \\
\hline Media used & PPTs, charts, video, handouts, etc. & \\
\hline Media availability & Which media, available when? & \\
\hline Delivery profiles ST & Profile for each speaker & \\
\hline
\end{tabular}




\begin{tabular}{|l|l|l|}
\hline Delivery types & Extempore, manuscript, mix, media used & \\
\hline Speaker language & (Non-)native, good, average, poor & \\
\hline Length of presentation, dynamics & Flow, speed (per speaker) & \\
\hline Working time and breaks & Time schedule of event & \\
\hline Additional working time & $\begin{array}{l}\text { Coordination, dialogue interpreting during } \\
\text { breaks, meals }\end{array}$ & \\
\hline Interpreting requirement & Types of interpreting required & \\
\hline Team profile & $\begin{array}{l}\text { Qualifications, professional experience, references } \\
\text { (per interpreter) }\end{array}$ & \\
\hline Interpreter delivery profiles & $\begin{array}{l}\text { Output-related parameters per interpreter } \\
\text { (content, form, delivery, at macro and micro level) }\end{array}$ & \\
\hline Addressee profiles & Experts, laypeople, general public & \\
\hline Listeners per language & Percentage, status & \\
\hline Composition of audience & Languages, cultures, degree of heterogeneity & \\
\hline Feedback to interpreters & Types, extent, source & \\
\hline Relay interpreting & Percentage, directions, languages involved & \\
\hline
\end{tabular}

\begin{tabular}{|l|l|l|}
\hline Post-process & Contract-specific & \\
\hline Confidentiality & Public / confidential / classified & \\
\hline Management of documents & Return / further processing & \\
\hline Organization of post-processing & $\begin{array}{l}\text { Time between event and post-processing, } \\
\text { degree of diligence }\end{array}$ & $\begin{array}{l}\text { Frequency of self-recordings made and reviewed, } \\
\text { checks on notes }\end{array}$ \\
\hline Self- evaluation & Feedback, user satisfaction, complaints & \\
\hline Contact with client &
\end{tabular}

\begin{tabular}{|l|l|l|}
\hline & General & \\
\hline Technological upgrading & $\begin{array}{l}\text { PC, laptop, E-Mail, mobile phone, data bases, e- } \\
\text { dictionaries, other software, print media }\end{array}$ & \\
\hline Maintenance of own glossaries & Updating of entries and structure & \\
\hline Further training & Frequency, subjects & \\
\hline Further linguistic training & Ways and methods, intensity & \\
\hline Specialization & Type of measures taken & \\
\hline
\end{tabular}

Data collected on the basis of the above datasheet may serve as a basis for a refined profile of interpreters' professional activity. With this, it should be possible to draw up a macro-level profile and, at the same time, analyse individual micro-level problems by making use of the instruments developed by interpreting researchers. Most parameters can be elaborated on in the light of existing models (e.g. delivery profiles according to Pöchhacker's and/or Vuorikoski's methods). Isolated occurrences can be seen in a larger context and explained accordingly. Thus, source and target text can be viewed from a multifaceted perspective.

In an adapted form, such an approach might also serve as a tool for quality assurance applicable to other types of interpreting. When community interpreting or dialogue interpreting is to be studied, data on technical equipment may not be as relevant, whereas more detailed information on peri-process conditions (such as 
type of communication act, interactants, their respective status, (agreed) role of the interpreter) is needed.

\section{Conclusion}

On the basis of the scheme set out above, individual part processes can be studied and more data on conditions of work and cooperation by the other players in conferences can be obtained. Some of the data collected may be of interest to professional associations, covering questions such as by whom interpreters are recommended or how much time it takes to draw up a quotation. Other information, such as booth position, anticipated and actual number of languages and directions, may be of interest to organizers and should be made available to them, in the hope of securing closer cooperation between them and interpreters. If Vuorikoski stipulates the "informed" interpreter (Vuorikoski 2004: 46f) as well as collaboration between speakers and interpreters (Vuorikoski 2004: 15), the author of this article would add that information and collaboration are of the essence between all parties involved (client representatives, agency and technical staff, speech and ghost writers), especially in cases where conferences are complex and involve many languages; interpreters should be consulted beforehand so as to take account of communication needs (and interpreters' needs) in due time before problems arise. "Talk to your interpreters" is a recommendation made by the EU DG for Interpretation, by AIIC and many national professional organizations (cf. also Mack 2002: 117). It should be clear to all in advance who expects whom to do exactly what in a given scenario, what participants expect from interpreters and vice versa. This will help interpreters fulfil the expectations of speakers and listeners alike, and help all those involved understand which limitations are intrinsic in mediated multilingual communication and what they can do to achieve an optimum result. Competence in organizing multilingual interpreted events means being aware of these constraints and taking due account of them. In some cases, it is possible to determine in advance which preferences a client or and audience has, even if this does not necessarily correspond with interpreters' preferences (e.g. IT subjects where interpreters are requested to use in-house jargon, i.e. 'English at its worst,' and not to bother about target-language style).

If it is true that conference organizers are tempted to resort to the services of conference interpreters only when the topics are of a general nature and to prefer the use of English by all when the topics are very complex or technical (Vuorikoski 2004: $15)$, this constitutes a serious challenge to the profession. Conference interpreting is intended to formally put all participants on an equal basis and contributes to optimizing communication in multilingual settings. Interpreters should do everything they can to be able to make that contribution and the users of their services should be made to understand its importance.

If it is agreed that quality assurance does not relate to the text produced by the interpreter alone but includes processes required to be able to produce such a text, the next step is putting this insight into professional practice. The approach suggested above can be used by individual interpreters who are interested in having information on the conferences they work at, or by groups of interpreters or agencies eager to obtain some information on how fellow interpreters whom they wish to hire tend to proceed, or, for that matter, by conference organizers, or, last but not least, by 
trainers who are seeking to raise trainee awareness of the overall conditions and requirements of any interpreting act.

\section{REFERENCES}

BüHleR, H. (1986): "Linguistic (Semantic) and Extra-Linguistic (Pragmatic) Criteria for the Evaluation of Conference Interpretation and Interpreters," Multilingua 5-4, p. 231-235.

Déjean le FéAL, K. (1982): "Why Impromptu Speech Is Easy to Understand," N. E. Enkvist (ed.), Impromptu Speech. A Symposium, Abo Research Institute of the Abo Academi Foundation, p. 221-239.

DéJEAn le FÉAL, K. (1990): "Some Thoughts on the Evaluation of Simultaneous Interpretation," D. Bowen and M. Bowen (eds.), Interpreting - Yesterday, Today and Tomorrow, American Translators' Association, Scholarly Monograph Series, Vol. IV. Binghamton: State University of New York, p. 154- 160.

Garzone,G. (2002): "Quality Norms in Interpretation," Garzone and M. Viezzi (eds.), Interpreting in the 21st Century. Proceedings of the 1st Conference on Interpreting Studies, Forlì, University of Bologna (9-11 November 2000), Amsterdam/Philadelphia: Benjamins, p. 107-119.

Gile, D. (1988): "Le partage de l'attention et le 'modèle d'effort' en interprétation simultanée," The Interpreters' Newsletter 1, p. 27-33.

Kahane, E.(2000): "Thoughts on the Quality of Interpretation," Communicate! Issue 4, May 2000, on AIIC homepage (AIIC Online) <http://www.aiic.net/ViewPage.cfm/page197.htm> (as of 23-09-00).

Kalina, S. (1995): "Dolmetschen und Diskursanalyse - Anforderungen an Dolmetschleistungen," Beyer, M. \& Diller, H.J. \& Kornelius, J. \& Otto, E. \& Stratmann, G. (Hgg.), Realities of Translating, anglistik und englischunterricht, Heidelberg, Winter, p. 233-245.

Kalina, S. (1998): Strategische Prozesse beim Dolmetschen. Theoretische Grundlagen, empirische Untersuchungen, didaktische Konsequenzen, Language in Performance Bd. 18, Tübingen, Gunter Narr.

Kalina, S. (2002): "Quality in Interpreting and Its Prerequisites - A Framework for a Comprehensive View," Garzone, G. and M. Viezzi (eds.), Interpreting in the 21st Century. Proceedings of the 1st Conference on Interpreting Studies, Forlì, University of Bologna (9-11 November 2000), Amsterdam/Philadelphia, Benjamins, p. 121-130.

Kalina, S. (2004): "Es gilt das gesprochene Wort ... - Wege der Qualitätsforschung im Dolmetschen," Fleischmann, E. \& Sснмitт, P.A. \& Wotjak, Gerd (Hgg.), Translationskompetenz. Tagungsberichte der LICTRA Leipzig International Conference on Translation Studies, 4.-6.10. 2001, Tübingen, Stauffenburg, p. 751-761.

Косн, А. (1992): “Übersetzen und Dolmetschen im ersten Nürnberger Kriegsverbrecherprozeß Mehrsprachigkeit in internationalen Gerichtsverbrechen," Lebende Sprachen 37-1, p. 1-7.

Конn, K. and S. Kalina (1996): "The Strategic Dimension of Interpreting," META 41-1, p. 118 138.

Kopczynski, A. (1994): "Quality in Conference Interpreting: Some Pragmatic Problems," S. LAMBert \& B. Moser-Mercer (eds.), Bridging the Gap: Empirical Research on Simultaneous Interpretation. Amsterdam/Philadelphia, Benjamins, p. 87-99.

Kurz, I. (2001): “Conference Interpreting: Quality in the Ears of the User," META 46-2, p. 394409.

Kutz, W. (1997): “Gut für wen? Zur Bewertung von Konsekutivdolmetschleistungen,” E. FleisCHmann, \& W. Kutz \& P.A. Sснмітт (Hgg.), Translationsdidaktik. Grundfragen der Übersetzungswissenschaft, Tübingen, Gunter Narr, p. 243-254.

MACK, G. (2002): "Die Beurteilung professioneller Dolmetschleistungen,” J. Best \& S. KaLina. (Hrsg.), Übersetzen und Dolmetschen. Eine Orientierungshilfe, UTB 2329, Tübingen, Francke Verlag, p. 110-119. 
Moser-Mercer, B. (1996): "Quality in Interpreting: Some Methodological Issues," The Interpreters' Newsletter 7, p. 43-55.

Pöchнacker, F. (1994): Simultandolmetschen als komplexes Handeln. (=Language in Performance 10), Tübingen, Gunter Narr.

Pöchhacker, F. (2001): "Quality Assessment in Conference and Community Interpreting," META 46-2, p. 410- 425.

Pöchнacker, F. (2002): “Researching Interpreting Quality: Models and methods," G. Garzone and M. Viezzi (eds.), Interpreting in the 21st Century. Proceedings of the 1st Conference on Interpreting Studies, Forlì, University of Bologna (9-11 November 2000), Amsterdam/ Philadelphia, Benjamins, p. 95-106.

Shlesinger, M. (1994): "Intonation in the Production and Perception of Simultaneous Interpretation,” S. Lambert \& B. Moser-Mercer (eds.), Bridging the Gap: Empirical Research on Simultaneous Interpretation. Amsterdam/Philadelphia, Benjamins, p. 225-236.

Shlesinger, M. (1997): “Quality in Simultaneous Interpreting: Round Table Report,” Y. Gambier, D. GILE and C. TAYLOR (eds.), Conference Interpreting: Current Trends in Research, Amsterdam/ Philadelphia, Benjamins, p. 123-131.

Snelling, D. (1989): “A Typology of Interpretation for Teaching Purposes," L. Gran \& J. Dodds (eds.) (1989), The Theoretical and Practical Aspects of Teaching Conference Interpretation. Proceedings of the Trieste Symposium, 1986, Udine, Campanotto, p. 141-142.

Van Besien, F. and C. Meuleman (2004): "Dealing with Speakers' Errors and Speakers' Repairs in Simultaneous Interpretation. A Corpus-Based Study," The Translator 10-1, p. 59-81.

Viezzi, M. (1999/20034): “Aspetti della qualità nell’interpretazione“, C. FAlbo, M. Russo \& F. Straniero Sergio (eds.), Interpretazione Simultanea e consecutiva - Problemi Teorici e Metodologie Didattiche, Milano, Ulrico Hoepli Editore, p. 140-151.

Vuorikoski, A.-R. (2004): A Voice of its Citizens or a Modern Tower of Babel? The Quality of Interpeting as a Function of Political Rhetoric in the European Parliament, Tampere, Tampere University Press. 